\title{
O texto que existe antes da frase: apontamentos sobre escrever, ler e performar
}

The text that is before the sentence: notes on writing, reading and performing

Bernardo Romagnoli Bethonico

Universidade Nova de Lisboa

\section{Resumo}

Traçamos uma relação entre escrita, leitura e performance a partir da escritora Maria Gabriela Llansol (1931-2008) e da experiência iniciada em 2010 junto ao coletivo C.E.M. - Centro em Movimento - Lisboa. Salientamos essas práticas como inerentes à singularidade de cada corpo, em diálogo com a abordagem de Paul Zumthor sobre a performance e a comunicação poética. O corpo e o espaço são assim investigados como elementos não abstratos de um texto escrito, indissociáveis da sua criação e recepção. Pretendemos documentar dessa forma a prática sensível da palavra como um campo expandido, em abertura ao que há de não verbal nela própria. Esta é defendida aqui como uma experiência atenta aos afetos corporais e à relação com o espaço. O artigo propõe finalmente pensar a relação entre corpos leitores/escritores/performadores como um conjunto de singularidades que aprendem a ler, além da linguagem verbal, também o que há antes da frase.

Palavras-chave: leitura, escrita, performance, corpo, espaço.

\begin{abstract}
We draw a relationship between reading, writing and performance from the writer Maria Gabriela Ilansol, and the experience started in 2010 with the collective C.E.M (Centro Em Movimento) - Lisbon. We emphasize these practices as related to the uniqueness of each body, in dialogue with Paul Zumthor's approach to performance and poetic communication. Body and space are therefore investigated as non-abstract elements of a written text, inseparable from its creation and reception. Thus, we aim to document the sensible practice of the word as an expanded field in opening to what is nonverbal in itself. This is advocated here as an experience concerned with corporeal affections and the relation with space. The article finally proposes to think the relation among readers/writers/performers-bodies as a set of individualities that learn how to read not only verbal language, but also what comes prior to the sentence.
\end{abstract}

Keywords: reading, writing, performance, body, space.

\section{0 texto que existe antes da frase}

Revista Digital do LAV - Santa Maria - vol. 9, n. 2, p. 245 - 260. - mai./ago. 2016 ISSN 1983 - 7348 http://dx.doi.org/10.5902/1983734822442 
o que advém do texto é a construção da frase [...]

LLANSOL, Onde vais, drama-poesia?

O trecho acima é um convite a reconsiderar o nosso próprio entendimento do que seja um texto escrito. É comum, ao ouvir "texto", pensar em uma organização de palavras agrupadas em frases. O texto seria, assim, a soma de frases que formam uma trama de significados, numa espécie de unidade de significação com introdução, desenvolvimento e conclusão. Entretanto, no fragmento acima, o texto é apresentado como o criador das frases, não o resultado delas. Não há um passo a passo. A frase não está feita como peça para se encaixar a um todo.

Algo ocorre na construção da frase que define aqui o texto de outra forma. Alguma ação a faz surgir a partir de um texto que está antes. Podemos pensar que essa ação seja a escrita ou a leitura. Podemos imaginar que elas sejam partes de uma arquitetura que se projeta com base nesse texto anterior.

E o que seria o texto? Aqui não cabe olhar para ele como um território do qual simplesmente extraímos algo que já se encontrava lá pronto. $O$ texto não é algo a ser explorado como um latifúndio ou uma mina. Aqui também não cabe pensá-lo como fonte. Ele não guarda conteúdos intactos a serem explorados ou colonizados. Esse estranho texto já começou antes de começar e fala por si. Tem voz própria sem frases. Já está acontecendo antes de ser construído. Existe antes de ser visível.

Mas o que seria a leitura desse texto? Uma entidade abstrata e neutra, leitura com letra maiúscula desabitada de pessoa, de leitor, de respiração e de dia a dia? A partir do que existe antes da frase, convido a pensarmos a leitura como um processo, ou seja, um movimento inseparável da pessoa que lê ou da pessoa que deseja ler - aquela que se dispõe a construir a frase.

\section{Aprender a ler e a escrever}

Toda construção estabelece uma relação com o tempo. Não é de uma hora para a outra que se fazem desenhos e que se levantam casas. Aprender a fazer coisas com o tempo não é estabelecer garantias de que tudo o que vemos permanecerá da forma como pensamos. Da mesma forma, ler ou escrever algo vai gradualmente mudando algumas 
das nossas formas de ver. A palavra "construção" na epígrafe que abre este artigo sugere que o contato com um texto, como a obra de uma casa, se vale de materiais diversos. Considerando que a frase aparece depois desse texto, poderíamos encontrá-lo em palavras soltas e mesmo lê-lo naquilo que ainda tem desejo de ser escrito, em uma linguagem antes da linguagem, sem palavras. A leitura, então, é uma ação que se move entre diferentes materialidades, realidades e linguagens, a partir do corpo irrepetível de alguém, do olhar singular do leitor e dos recortes que este faz para realizá-la.

Entretanto, sabemos que um texto não é somente algo a ser lido, mas também a ser escrito. Ele vai acontecendo no agora do cara a cara com a página branca, no mundo daquele que considera a sua movimentação interior, no mundo daquele que inquieto se lê para escrever ou produzir algo que, entretanto, vibre endereçado ao fora.

Um texto, por esse olhar, estará em estreita relação com um fôlego de fazer frases, mas sem se confundir com elas. Ele pode ser encontrado nas visões e na condição de produção singular de quem as escreve. O texto está no espaço e nas relações que o corpo estabelece, está na interioridade, nos cheiros, nos quartos, nos pensamentos e nos vislumbres. Ou não. Poderá estar também naquilo que não é perceptível ou que só lentamente começa a ser notado. Talvez por isso, o texto seja intransmissível enquanto algo que existe antes da frase, pois só pode ser captado através de uma espécie de documentação, nas frases que imprime.

No entanto, enquanto isso, o texto também existe antes da leitura, na visão e no fazer particulares àquele que lê. Lado a lado com linguagens não verbais, as frases surgem com a leitura e com as condições em que me coloco a ler. Como para quem escreve, as frases não se dão fora das relações entre coisas e pessoas. Não existem enquanto entidades completas. Para quem lê, as frases têm a especificidade do momento em que são lidas - são convites que alguém fez e em que se pode ou não entrar. Convocam respirações, traços, focos, imagens. Nessa perspectiva, a frase advém, vem depois, acontece a partir de uma leitura e de um corpo que já estava lendo outras coisas antes dela. A frase começa no meio de alguém, que habita algum lugar.

Quando as letras encontram-se escritas ou publicadas, a construção de uma frase acontece no encontro ou no confronto entre o que está escrito e a pessoa que deseja ler - aquele imprevisível, aquele qualquer um para quem se publica ou para quem se joga uma garrafa no mar. O fazer da frase é um fluxo no leito de um texto que está a acontecer. Esse texto é o processo que é uma pessoa.

Entretanto, construir a frase de que falamos não é necessariamente construir base para uma progressão, com início, meio e fim. Uma vez que descobrimos algo, é preciso 
descobri-lo de novo. Senão a leitura da frase fica engessada. Como nos desenhos que se fazem na água de um rio, uma combinação de traços não se repete idêntica em nosso corpo que lê. Há aqui uma fecundidade no ato de ler, muito próxima da ação de criar, pois quem constrói uma frase a compõe com materiais dispersos, vocábulos, silêncios e desejo. Quem é que sabe como vão durar? Talvez pela escrita ou pela gravação de uma fala, não já exatamente pela leitura.

$\mathrm{Na}$ criação do que sempre se permite recriar, aparecem juntos o escritor e o leitor. Para aquela que aqui inicia a nossa reflexão, Maria Gabriela Llansol, ${ }^{1}$ esses são os dois polos que figuram no texto, que é a mais curta distância entre os dois pontos. E não há um sem o outro: "escrevo na plena posse de minhas faculdades de leitura", diz Llansol (1983, p. 12). Engana-se quem pensar que não lemos na plena posse de nossas faculdades de escrita. Corpos leitores, entretanto, estão em geral acostumados a se negarem enquanto corpos que trazem o seu próprio texto. Estão habituados a aceitar a escrita como dizer unilateral, em relação a uma cartilha a ser supostamente aprendida, silenciando o olhar como lugar de aprender a fazer as próprias perguntas e de aprender a reconhecer outros olhares.

Ler bem não é só decodificar signos ou reconhecer discursos, pois se aproxima muito de olhar. Uma leitura atenta emana uma paisagem, algo que alguém percebe em torno de si. Um olhar atento, por sua vez, não deixa de ler. A fluidez de estados de atenção entre ler e olhar convoca conversas entre leitores. Olha-se para fora de um verbo unitário ou além de uma palavra escrita que diz uma verdade. O texto é pululante - mora antes de

\footnotetext{
${ }^{1}$ Maria Gabriela Llansol (1931-2008) é uma escrevente, como ela mesma gostava de se chamar. Nasceu em Lisboa e passou vinte anos exilada na Bélgica. A sua obra, sempre em prosa, é marcada por uma dicção radical que, ao mesmo tempo em que resgata figuras históricas de rebeldes e místicos, não aceita a representação como forma de abordar uma potente "restante vida" que insiste apesar de todos os derramamentos de sangue da história. Concentrando-se mais nas forças do que nas formas, Llansol aposta na escrita como gesto de conexão do pensamento com o corpo, sugerindo uma temporalidade poético-revolucionária que não conhece a morte ou o fim, como visto nas versões oficiais e na lógica da representação. Naquilo que chama de espaço edénico, a linguagem estética é a resistência a uma tradição que insiste em separar o pensamento da escuta dos afetos, cultivando o medo. A conviç̧ão é a de que o espaço edênico "não é fixo, como sugere a tradição, mas elaborável segundo o desejo criador do homem" (LLANSOL, 2003, p. 146). Assim, a crítica feita por Llansol vê um encontro entre a encenação política e o aborto das sensibilidades, colocando o próprio ato de aprender a ler em questão. Como diz Augusto Joaquim, a obra de Llansol é "dos raros textos a dar deliberadamente voz às forças inintencionais (vulgo, bombardeio constante de estímulos sensoriais). Que eu saiba, é nele que, pela primeira vez, as massas de início são centrais. Vemo-las agir, evoluir, pensar, sofrer, convictas de que o espaço edénico - o Grande Exterior -, além de indestrutível, é o único destino para uma espécie comunicante, contradizendo à letra a pretensão dos grupos estratégicos que persistem em definir para o humano um destino de morte e de impotência." (JOAQUIM, 2007, p. 208.)
} 
escrever e pode ser acessado se quisermos aprender a ler o que se movimenta em nós, seres criadores de linguagem. Os humanos apenas começam a trilhar aí caminhos que realmente os coloquem em jogo nas práticas de escrita e de leitura. Digo isso por experiência própria e pelo diálogo com colegas sobre a dificuldade inerente a essas práticas, agravada pelo acanhamento generalizado em compartilhar ou discutir trabalhos no ambiente universitário, pelo esforço que se deve fazer para escutar as ideias de outros e também para escutar as próprias, e a interseção das próprias ideias com as de outros. Sublinho aqui a necessidade de se exercitar o ser livremente, na academia ou não, apesar de qualquer hierarquia fantasmante. Da mesma forma, há que se sustentar uma ecologia da linguagem que se empobreceu com os protocolos escolares, por meio do próprio tônus que se dá entre corpos que discutem e aprendem, ainda que pareça não haver, na maior parte das vezes, escolas ou alunos abertos a diálogos com consequências mais férteis para a leitura e a escrita.

Este texto, então, documenta minha experiência no programa de investigação artística e estudos do corpo FIA - Formação Intensiva Acompanhada, entre 2011 e 2012, no c.e.m. - Centro em Movimento, Lisboa, em confluência com a pesquisa de mestrado realizada na UNL - Universidade Nova de Lisboa, "A voz começante de Maria Gabriela Llansol". O c.e.m. é uma estrutura voltada ao estudo do movimento enquanto forma de conhecimento. Produz ações de corpo principalmente no espaço público e discursos críticos sobre o contemporâneo, convidando à contaminação permanente da dança por outras artes, pela rua e pela teoria. (Des)afinado com a pesquisa acadêmica em literatura, pratiquei dança e também o que ali Sofia Neuparth e Margarida Agostinho chamam de escrita em estado de dança e leitura em estado de dança. Acabei fazendo da leitura de Llansol um estudo indissociável dos outros sentidos corporais trabalhados no movimento. Para Llansol, "a vibração pelo vivo e pelo novo" é o que "sentimos fisicamente com o sexo que temos, o que as imagens vêm procurar em nós", um sexo de ler (LLANSOL, 1994a, p. 12). Há quem diga tesão. Retornando ao c.e.m. para um estágio de criação desde 2015, posso agora, ao lado das práticas de fisicalidade da escrita ali propostas por Margarida Agostinho, reelaborar o fulgor das reflexões desenvolvidas nos anos anteriores, que apresentarei ao longo do artigo.

\section{Escrever, ler, performar, estar junto}


LLANSOL, Onde vais, drama-poesia?

A construção da frase dá-se numa experiência que não se reduz ao movimento dos olhos e ao empenho da energia interior de quem lê: a experiência da página ou qualquer outro suporte está em confluência com a experiência do espaço. Como é que me relaciono com a minha própria presença em um texto? Como é que chego a um espaço e como deixo ele chegar até mim? Onde estou comigo mesmo quando algo soa relevante? E quando não interessa, posso identificar onde habito e ter alguma consideração sobre o que vejo? Essas são perguntas que dizem respeito aos processos tanto da escrita quanto da leitura como praticadas em grupo no c.e.m., através das propostas de Margarida Agostinho, que se dão ou no espaço público ou numa sala, cultivando um corpo "em ressonância com outros corpos, permeabilizando-se nas transformações e nas qualidades de paisagem que a relação com o outro, com o mundo e com a sua própria escrita vai trazendo" (AGOSTINHO, 2016, p. 1). Essa permeabilidade pede que o pensamento ou a ação se desdobrem para além de sua eficácia e se centrem na implicação do gesto em si, seja qual for a forma dele.

O espaço é o lugar onde se dão os encontros de escrever ou ler, seja em voz alta, em silêncio, na página, caminhando, deitado ou apoiado em outros corpos. Nesse espaço também se pode exercitar uma atenção móvel de olhar para outros lugares enquanto se continua a fazer o que se está a fazer.

Sendo a escrita uma actividade considerada solitária ela é nesta proposta acedida numa solidão acompanhada, estando cada performer ao mesmo tempo profundamente implicado no seu laço próprio com o mundo e simultaneamente aberto às transformações de paisagens internas que o outro potencia. (AGOSTINHO, 2016, p. 1)

Cabe aqui apontarmos a permeabilidade da palavra espaço, que poderia se confundir com mundo. Um espaço pode ser fisicamente tanto uma extensão ideal, sem limites, contendo tudo o que fosse possível conter, quanto uma extensão de limites tangíveis (TSCHUMI, 2004). Ele pode ser imagem de pulsões desejantes e hábitat de atmosferas individuais, enquanto se usa a palavra "espaço" também para lugares calculadamente percorríveis, estabelecidos pelos números ou selvagemente erguidos pelas forças naturais. O espaço, como o abordamos aqui, é sempre relacional. Seja relacionando-nos com pessoas ou com coisas, lidamos com um "entre" que o espaço permite e que, entre proximidade e distância de um texto, tem elasticidades variáveis. 
Para o teórico Paul Zumthor, a ligação entre espaço e texto é indispensável. Por ligar a poesia intimamente ao acontecimento performático e vocal, o pensamento de Zumthor é colocado aqui lado a lado com a reflexão que fazemos com Llansol, por resistir à própria literatura como quimera moderna baseada exclusivamente na escrita, utilizando a categoria do espaço como inegável fato associado à experiência de ler.

O espaço, em Zumthor, motiva uma diferenciação entre texto e obra. É a partir dessa diferenciação que o autor relê o antigo elo entre o poético e o que chamamos hoje de performance (ZUMTHOR, 2007, p. 75-87). Vejamos em que consiste. O texto, para ele, é uma sequência mais ou menos longa de enunciados que se caracteriza por sua semioticidade, num sistema de comunicação vigente em uma sociedade. Entretanto, há algo que pode escapar em parte a esse sistema e é o estilo de um autor.

A obra, por sua vez, abrange o texto e a enunciação dele. Na especificidade de seu fenômeno que se dá no espaço, com múltiplos elementos férteis em sua efemeridade, a obra é entendida como performance. Em seus estudos iniciais, como medievalista, Zumthor identifica manuscritos de poesia europeia enquanto documentos da vocalidade de menestréis e trovadores, que traziam o próprio corpo-voz como suporte da palavra como no sertão brasileiro, a poesia era normalmente recebida na Idade Média através da voz e da música. A teoria de Zumthor foi, a partir daí, se interessando a documentar os sentidos da voz humana, abordando-os também na escrita. Aí os afetos do espaço que abriga a situação de criação poética são fundamentais, independentemente de suas condições de produção: para Zumthor, os fatos corporais também estão relacionados ao ato de ler uma página em silêncio. O olhar deste autor nos permite então contemplar a palavra como performance poética - criação que se dá no espaço e no tempo convidando a uma atenção expandida, não exclusivamente verbal e variável de acordo com o recorte do espectador.

A noção de "literatura" é historicamente demarcada, de pertinência limitada no espaço e no tempo: ela se refere à civilização europeia, entre os séculos XVII ou XVIII e hoje. Eu a distingo claramente da ideia de poesia, que é para mim a de uma arte da linguagem humana, independente de seus modos de concretização e fundamentada nas estruturas antropológicas mais profundas. [...] Estou particularmente convencido de que a ideia de performance deveria ser amplamente estendida; ela deveria englobar o conjunto de fatos que compreende, hoje em dia, a palavra recepção, mas relaciono-a ao momento decisivo em que todos os elementos 
cristalizam em uma e para uma percepção sensorial - um engajamento do corpo. (ZUMTHOR, 2007, p. 12 e 18)

A noção de performance convoca as pulsações do ritual, da tragédia, do canto, da dança no que é poeticamente comunicado hic et nunc, no sentido da irrepetibilidade dos fenômenos de ler ou de escutar. O diálogo implícito entre poeta e leitor é um constante movimento. Como vimos com Llansol, quem escreve e quem lê são eles próprios textos em processo. São eles que constroem a frase, ou seja, não há uma abstração pronta para se extrair da palavra. Ela precisa vibrar em alguém. Da mesma forma, a ação performática não é absoluta. O exato instante e o exato local em que me encontro com uma obra, seja para realizá-la ou para estar com ela, abrangem múltiplos elementos significantes, sistematizados ou não no contexto cultural. Na performance, sempre alguma coisa "transborda, recusa-se a funcionar como signo" (ZUMTHOR, 2007, p. 75). Ou como o teatro para Artaud, que é "palavra ilegível", "anterior à escritura", em que "o signo ainda não se separou de sua força" (ARTAUD citado por ZUMTHOR, 2007, p. 61).

A obra performática convida à leitura de elementos marginais, que perdem o estatuto de código e se abrem para a não significação ou para a significação desconhecida, com toda a resistência poética que pode advir do que não entendemos discursivamente. Lidamos com a percepção do que é um gesto, uma entonação, um olhar, uma temperatura, uma tensão que se dá entre corpos e entre coisas. De forma análoga, o espaço da percepção sensível da linguagem verbal está aberto para a voz alta, a escuta, a contingência, o prazer gráfico, os sonhos e também o próprio espaço físico onde se lê o livro, paisagem.

No seu trajeto pela história do pensamento e pela história do que se cantou, desenhou, atuou ou escreveu, o sensível que se dá na provisoriedade do estar encontra-se nas sombras e em condição de errância, resto, excedendo à legibilidade comum que dele podemos documentar numa linguagem. O próprio nascimento tardio de uma área que estude as faculdades sensitivas na arte e o sentimento do belo, a estética, revela que há uma obscuridade no pensamento ocidental: "no século XVIII, Baumgarten designava a estética como o domínio do conhecimento sensível, um conhecimento 'claro' mas ainda 'confuso', que se opõe ao conhecimento 'claro' e 'distinto' da lógica" (SANTOS, 2008, p. 232).

De fato, para Paul Zumthor, a comunicação poética é aquela que tem "tendência ou aptidão para gerar mais prazer do que informação" (ZUMTHOR, 2007, p. 64) e daí o seu caráter confuso, porém arejado, pois ela não propõe algo a priori. Depende da própria experiência de ecoar ou não ecoar no corpo. Ao privilegiar o caráter experiencial de algo que na idade moderna recebeu o nome de literatura - termo que indica um sistema 
histórico-social para uma experiência com linguagem geradora de prazer, digamos -, Paul Zumthor nos lembra que a comunicação poética é um ato que "acentua o elemento hedônico sem que a informação seja necessariamente negada" (ZUMTHOR, 2007, p. 64). Entretanto, o prazer não é nunca a garantia de comunicação com o que lemos. Podemos estar unicamente a projetar-nos num livro, sem levar em conta uma espécie de drama que se dá numa camada mais profunda da leitura. Para que haja o diálogo que ocorre num drama há que se ter pelo menos dois lados e um deles é o outro, é o desconhecido, é o negativo "você" em relação ao positivo que diz "eu": leio um texto e, quando me permito desconfiar do que leio, algo se estremece no limite do que eu conhecia. Faz-se possível redesenhar o que vejo.

Considerar a prática da leitura como a experiência singular de cada um, experiência sobre a qual posso escrever e falar, explicitando as diferenças e estranhezas do sensível que me ocorre, sem ter que copiar uma visão unitária considerada mais sincera ou elegante, favorece a formação de uma comunidade de leitores. Esse espaço coletivo tem afinidades, repulsas, perguntas e direcionamentos que podem ser inscritos ou dançados nele. Entretanto, o que faz uma comunidade não é a unanimidade, mas o dissenso (GABRIEL, 2016). Por isso o espaço de leitura coletiva nos convoca a ser de maneiras que ainda não conhecemos em nossos prazeres. Ler com o corpo não significa excluir a abstração. Como nos acena Luís Alberto Brandão, há muitas relações além das que colocamos em foco.

[...] a operação relacional é fruto de uma faculdade abstrativa. [...] não se estabelece uma relação entre referências se se crê que estas são meras projeções da relação, se não se aceita que estas possuem, de certa maneira, manifestação própria, ou seja, que, independentemente daquela relação, possuem algum tipo de realidade, o que não significa entendê-las segundo um prisma ontológico (pelo qual possuiriam um ser essencial, um "em si", algo que as fundamenta a si mesmas), mas simplesmente que são definidas por outras relações que não a que foi colocada em foco. Trata-se, assim, não de recusar a existência de uma "corporeidade" ao espaço, mas de ressaltar que "corpo" não pode ser considerado nem como manifestação autofundante, nem como noção autoevidente. (BRANDÃO, 2007)

Estar num espaço e relacionar-se com ele se aproxima de ler. A leitura ela mesma também funda um tipo de espaço. Nossos corpos que leem não são óbvios, nosso texto 
não está dado de cara. É preciso procurar a especificidade do espaço que habitamos ao ler. Pode ser que eu tenha que folhear um livro durante muito tempo, antes de lê-lo do início ao fim. Pode ser também que um dia esteja mais para ler deitado; noutros, sentado; noutros, em voz alta. Pode ser que eu queira escutar um livro pela voz de um amigo, numa praça. Pode ser que eu queira lê-lo para alguém, na escada.

Quando ao ler construímos uma frase, o sentido semântico e o sentido sensório permeiam o espaço, trazendo algum sabor específico. Quando me sento ao lado de uma pessoa que lê no metrô ou no ônibus ou numa praça, há um tipo de interesse que surge, não necessariamente em relação ao livro ou ao pensamento, mas antes sou tocado pela atmosfera que essa pessoa está a criar em torno de si (MOLDER, 1999). Não me basto no meu próprio corpo.

A leitura que desejo praticar convoca corporalmente. Compartilha um espaço com outros corpos. Como diz Llansol sobre o seu texto: "Sempre fui entendendo que se tratava de uma intimidade exposta aos olhares dos outros" (LLANSOL, 1994b, p. 20). Os seus livros, entretanto, não trazem descrições de uma encenação bem-feita da vida privada, ainda quando forem chamados de diário. Há um tipo de atenção ao próprio universo sensível que só se dá quando nos implicamos em nossa experiência sem sermos personagens de nós mesmos. Há uma disposição a arriscar a própria identidade, seja como for que isso se dê. Há uma coragem para lidar com o fragmento, que nessa autora começa no final dos anos 1970, com O livro das comunidades, e vai até 2007 , com Os cantores de leitura. Algo em sua escrita abre caminho a outros em sua própria linguagem de outros, na margem da instituição literária da modernidade. ${ }^{2}$

A epígrafe desta seção nos diz que o que advém do espaço é o seu sentido. O sentido do espaço bem pode se dar numa resistência a espaços urbanos tidos como lugares de corpos alheados da escuta de si, requisitados a todo tempo por uma série de estímulos que os preveem enquanto vidas a serem gerenciadas. Aí o ato de ler e de recriar a presença nos espaços públicos com prazer, enquanto resistência principalmente ao descaso com as cidades contemporâneas, pode-se dar em grupos que se reúnem regularmente para praticar. Sutilmente outra atmosfera se faz na rua quando ler/escrever se faz em ajuntamento de corpos. Ler encontra-se com os ruídos de uma matéria que sublinhamos em Llansol para o ato de escrever: "Progressivamente, sentimos um texto. Isso, a que chamei Esse, a brotar de imagens, de cenas, de

2 "Não há literatura. Quando se escreve só importa saber em que real se entra, e se há técnica adequada para abrir caminho a outros." (LLANSOL, 1998, p. 55) 
paisagens. E isso é mundo, é íntimo, é real, é rua. A nossa história do universo" (LLANSOL, 2000, p. 34).

A forma de ler hegemônica na cultura ocidental restringiu-se à decodificação da escrita verbal. Entretanto, a atividade ocular de percepção imediata, em sinergia com outras percepções, acontece num instante anterior à decodificação de signos e à percepção semântica. Ler o convite que faz o texto seja ele qual for e talvez duvidar dele, e talvez mergulhar nele, é antes estar a todo momento a ler o que se faz em nós, prescindindo da língua, mas em contato com ela. Nosso olhar encontra-se distante. É um fato culturalmente menos importante do que um livro, constata-se. Um livro, no entanto, não é "[...] o objeto rápido de uma leitura; dissimula um mútuo: uma época e alguém" (LLANSOL, 1987, p. 45). Temos neste trecho de Llansol uma atenção ao que no humano não funciona como signo fixo. Uma época e um alguém são rastros que sobrevivem nas letras. Quando os conceituamos em nossas leituras, fogem rapidamente. São rastros e não entidades completas. A sua dança é feita na letra, na intradutibilidade mesma do que leio e não entendo e de repente entendo, só que aí talvez não mais. Prática que cria as suas próprias condições de produção, com os materiais que trago, com o possível excesso de uma sensibilidade difusa que acompanha a mancha do livro, anterior às disciplinas do corpo escolar e à compartimentação dos sentidos na razoabilidade. É esse excesso o traço fundamental da leitura, para Zumthor:

O corpo não está jamais perfeitamente integrado nem no grupo nem no eu. A operação de leitura é dominada por essa característica. [...] Os fatos corporais não são jamais dados plenamente nem como um sentimento, nem como uma lembrança, no entanto, não temos senão o nosso corpo para nos manifestar. (ZUMTHOR, 2007, p. 80)

O drama e a incompatibilidade não fazem parte de uma progressão narrativa com desfecho: o drama é constitutivo do próprio eu e do próprio corpo seja na experiência de estar com um livro ou fora dela. A construção da frase não é de um leitor abstrato: ele mesmo faz o sentido. Encontrar o sentido que vem da frase em confluência com o espaço é recriar a comunicação poética num cuidado com o que está fora do livro, ou seja, principalmente com o leitor/com o outro enquanto pessoa que traz um universo mais complexo do que o imaginável. Em uma carta aberta ao crítico Eduardo Prado Coelho, Maria Gabriela Llansol diz: "desde sempre tenho me norteado pelo princípio de que o texto precisa encontrar, não o leitor abstrato, mas o leitor real, aquele a que, mais tarde, acabei por chamar legente - que não me tome por ficção nem por verdade, mas por caminho transitável" (LLANSOL, 1999). Encontrar o sentido que vem da frase em 
confluência com o espaço é também um cuidado da própria escrevente consigo própria, enquanto presença que não subtraia a sensibilidade a códigos literários a ser banalmente reproduzidos, ou enquanto presença que conviva com os códigos sem se agarrar a eles. $\mathrm{O}$ texto precisa encontrar o leitor, não a autora mesma enquanto representação de si. 0 legente achará nela um caminho transitável, o texto.

Quem também nos revela uma preocupação com o corpo concreto que (se) lê é Virginia Woolf, no conto "A marca na parede". Trata-se, como em Llansol, de uma poética que tem inevitavelmente consequências políticas, biopolíticas, pois é incisiva em relação às formas de compartimentação das sensibilidades. Woolf, em 1917, prevê romancistas do futuro "deixando cada vez mais de lado as descrições da realidade". No trecho que citamos aqui, a escritora aborda a presença no espaço, a presença na página e o estar junto:

A todo o momento vou construindo uma imagem de mim própria, apaixonadamente furtiva, que não posso adorar directamente, porque se o fizesse, cairia imediatamente em mim e deitaria a mão a um livro num gesto de autodefesa. É curioso, com efeito, como uma pessoa protege a sua própria imagem de toda a idolatria ou de qualquer outro sentimento que a possa tornar ridícula ou demasiado diferente do original para ser verossímil. Ou talvez não seja assim tão curioso, afinal de contas? É uma questão da mais alta importância. Imagine-se que o espelho se parta, a imagem desaparece e a figura romântica rodeada pela floresta profunda e verde desfaz-se: fica apenas essa concha exterior da pessoa que os outros habitualmente veem - que insípido, oco, inútil e pesado se tornaria o mundo! Um mundo onde não seria possível viver. Quando no autocarro ou sobre os carris do metropolitano encaramos os outros, estamos ao mesmo tempo a olhar para o espelho; é por isso que se torna possível vermos então como os nossos olhos são vagos, vítreos. E os romancistas do futuro darão uma importância crescente a estes reflexos, porque não há apenas um reflexo, mas um número quase infinito deste género de retracções; aí estão as profundidades que os romancistas do futuro terão que explorar; esses os fantasmas que terão de perseguir, deixando cada vez mais de lado as descrições da realidade, pressupondo-a já suficientemente conhecida pelo leitor, 
como fizeram também os Gregos e Shakespeare, talvez - mas estas generalizações começam a parecer-me inúteis. (WOOLF, 1994, p. 43)

A escrita e a leitura, como aventuras do olhar e do estar, e não sistemas semióticos ou históricos, a escrita e a leitura como arriscar-se a perder a própria identidade no fazer, como retrações que temos diante do outro no espaço público, fundam o ofício de viver o dia a dia sem diferenciá-lo do fazer artístico. Como em certa prática da performance, não se fixam em apenas um tipo de atenção: vamos nos reconhecendo em oscilações de proximidade e distância, entre o agarrar e o largar, em nossas próprias afinações sensíveis.

\section{O indispensável}

A escrita, exercício que lida com a improbabilidade da intenção e com o desconhecimento dos efeitos de recepção, como a performance, sugere outras maneiras de estar junto, de "reconhecer-se nobre na partilha da palavra pública,/ do dom de troca com o vivo da espécie terrestre" (LLANSOL, 2000, p. 25). Estar junto, esse despedaçamento que sempre pode tornar-se constelação, poderia ser sem o retraimento de uma posição defensiva, que em geral assumimos "face a todos os fundamentalismos da crença e da razão" (LLANSOL, 1994b, p. 5). Estar junto poderia ser possível sem constranger a poesia que aparece selvagem no nosso dentro.

o que advém do texto é a construção da frase;

o que advém do espaço é o seu sentido; o que advém da manhã é o sentimento de perca; o que advém da noite é o recomeço da frase interrompida; assim cogitando caminhava

e abri a porta que dava para o teu rosto legente.

Não disse nada, a ouvir nos teus olhos o som da rua que entrava pelas janelas. (LLANSOL, 2000, p. 10.)

Como a autora vê os olhos de quem a lerá? Não há aí nada além das possibilidades que a escrita e a leitura oferecem ao corpo de graça. Abrir a porta para o rosto do legente, despossuir-se para se deixar ouvir em seus olhos o som do atual, movimento que nunca está só em mim, instala-se na própria potência que a escrita é - significação em deslocamento, lida em tempos e espaços diversos, e poder de decisão da pertinência de um ato de comunicação que cria as suas próprias condições no incerto. "Deixei de ouvir 
qualquer rumor e apaguei, sem poder dissolvê-la, a frase _ / o indispensável caía no mesmo lugar do sentido" (LLANSOL, 2000, p. 10).

A frase paira no espaço como uma poeira que muito lentamente se aquieta. Aquilo que é produzido numa frase interrompida é caco de dizer ainda assim dizendo, sucumbindo à intensidade do silêncio. Pelos olhos e gestos do leitor, é vestígio do que pode ser continuado. Gesto que, sem continuar, ecoa. Se o indispensável encontra-se também no apagamento da frase, há ainda a força que a acompanha aquém ou além de sua forma "que a escrita há-de acabar, que 'qualquer' vivo é uma arte de estar todo em si" (LLANSOL, 2000, p. 219). Na própria indivisibilidade da percepção contínua de um leitor que não impossibilite a relação página-espaço, a página como um mundo repleto de ruídos exteriores sugere, como numa montagem cinematográfica, um conjunto de cortes que formam um filme interior que nasce da leitura.

A página faz parte do vivo. E o corpo do leitor está repleto do seu próprio olhar. E também não é o olhar da página? Podemos desdobrar essa relação, atuar no próprio espaço em cortes, a partir do que lemos. Há aqui uma afinidade com a atenção em intervalos que a performance propõe para quem a cria e para quem a acompanha: "O olhar não para de escapar ao controle, registra, sem distinguir sempre, os elementos de uma situação global, a cuja percepção se associam estreitamente os outros sentidos" (ZUMTHOR, 2007, p. 72). A ligação entre leitura e espaço como experiências e como criações em relação possibilita uma abertura da atenção para textos que estejam antes das frases. Isso não se dá fora das sensações de um corpo que se singulariza e que se deixa estranhar. Defendemos então o escrito como exercício de escrita num movimento de autonomia, como lemos com Margarida Agostinho, no fanzine do c.e.m.:

[...] talvez qualquer coisa entre quem escreve e quem lê acontece, se dê, para além do que um está a dizer e do que o outro está a ler. Talvez qualquer coisa de escuta, se quem escrever estiver à escuta e quem estiver a ler também. Talvez esses corpos deixem passar entre si um movimento que os alinha momentaneamente. Mas poder-se-á estar à escuta sem esperar nada que escutar? Mas poder-se-á ler sem esperar que haja qualquer coisa a ser lida? As minhas melhores leituras são paisagens que insistem. Aparecem sem sentido no meio de uma conversa, a olhar o mar, quando ando de carro, a fazer esparguete ao jantar... desconfio que esses alinhamentos de escuta escritor-leitor quando atravessam deixam um lugar. Nesse lugar as paisagens insistem. (CENTRO EM MOVIMENTO, 2016) 
A identificação obcecada por espelhos, manuais e mestres que não apreciam o dissenso não encontra aqui terreno estável - "avanço por um caminho que não garanto", aventura-se Llansol (2000, p. 185). Os confrontos e encontros do dia a dia sugerem assim criações, leituras, incompletudes. Ou seja, a comunicação poética, que cria, que não se fixa ao que já estava mapeado no reino das informações, também não se fixa na forma ou no passo a passo do caminho, direcionando-se antes às forças que aprendem com a fragmentação. É um convite a que o próprio leitor duvide das formas plenas de entender e de sentir, incluindo aí a identidade como uma instância que não conhece a mudança e o outro. Para praticar essa leitura e essa escrita convido, então, a gente a arrastar cadeiras, a sair pelas portas e a criar espaços de respiro, de silêncio e de conversa por aí, nas ruas ou em outros lugares.

\section{Referências}

AGOSTINHO, Margarida. Corpos escrevendo sobre o chão. Lisboa-Porto: c.e.m/Espaço Mira, 2016. Prospecto.

BRANDÃO, Luis Alberto. Espaços literários e suas expansões. Aletria - revista de estudos de literatura. Poéticas do espaço, v. 6. Belo Horizonte: POSLIT, Faculdade de Letras da UFMG, 2007. Disponível em http://www.letras.ufmg.br/poslit/08_publicacoes_txt/ ale_15/ale15_lab.pdf. Acesso em 22 set 2012.

CENTRO EM MOVIMENTO-C.E.M. [Há uma espécie de escrito que se faz ao vento], Pedras '16 Fanzine n. 2, Lisboa, nov. 2015.

GABRIEL, Markus. O sentido da existência. Trad. Bernardo Romagnoli Bethonico. Rio de Janeiro: Civilização Brasileira, 2016.

JOAQUIM, Augusto. Nesse lugar. In: BRANCO, Lucia Castello; ANDRADE, Vania Baeta (Orgs.). Livro de asas - para Maria Gabriela Llansol. Belo Horizonte: Editora UFMG, 2007. p. 193-225.

LLANSOL, Maria Gabriela. A restante vida - Geografia de rebeldes II. Porto: Afrontamento, 1983.

LLANSOL, Maria Gabriela. Finita - Diário II. Lisboa: Rolim, 1987.

LLANSOL, Maria Gabriela. Lisboaleipzig 1 - o encontro inesperado do diverso. Lisboa, Rolim, 1994a.

LLANSOL, Maria Gabriela. Lisboaleipzig 2 - o ensaio de música. Lisboa: Rolim, 1994b. 
LLANSOL, Maria Gabriela. Um falcão no punho - Diário I. $2^{\mathrm{a}}$ ed. Lisboa: Relógio d 'Água, 1998.

LLANSOL. Carta aberta a Eduardo Prado Coelho, Ciberkiosk, n. 7, set 1999. Associação Espaço Llansol.

LLANSOL, Maria Gabriela. Onde vais, drama-poesia? Lisboa: Relógio d’Água, 2000.

LLANSOL, Maria Gabriela; MENDES, João. O espaço edénico. In: LLANSOL, Maria Gabriela. Na casa de julho e agosto - Geografia de rebeldes III. Lisboa: Relógio d'Água, 2003. p. 141-168.

MOLDER, Maria Filomena. Semear na neve. Lisboa: Relógio d'Água, 1999.

SANTOS, Maria Etelvina. Como uma pedra-pássaro que voa - Llansol e o improvável da leitura. Lisboa: Mariposa Azual, 2008.

TSCHUMI, Bernard. Questions of Space. New York: AA Publications, 2004.

WOOLF, Virginia. A marca na parede. In: WOOLF, Virginia. Contos de Virginia Woolf. Lisboa: Relógio d'Água, 1994.

ZUMTHOR, Paul. Performance, recepção e leitura. Trad. Jerusa Pires Ferreira e Suely Fenerich. São Paulo: Cosac Naify, 2007.

Enviado em: 30 de maio de 2016.

Aprovado em: 09 de agosto de 2016. 